\title{
Multimedialidad en la prensa digital. Elementos multimedia y sistemas de recuperación en los principales diarios digitales españoles
}

\author{
Por Javier Guallar, Cristòfol Rovira y Sara Ruiz
}

\begin{abstract}
Resumen: Se muestran los resultados de un estudio sobre la presencia de elementos multimedia en los diarios digitales españoles de mayor audiencia a lo largo de un período de seis meses (de octubre de 2009 a marzo de 2010), así como los sistemas de búsqueda y recuperación de esos contenidos. Las principales conclusiones son: desigual presencia de fotografía, vídeo y gráficos; estabilidad y no aumento de elementos multimedia durante el período estudiado; y diferencias importantes en la calidad de la búsqueda multimedia.

Palabras clave: Periodismo digital, Prensa digital, Diarios digitales, Multimedia, Fotografía, Vídeo, Gráficos, Audio, Búsqueda, Hemerotecas digitales.
\end{abstract}

\section{Title: Multimedia in digital} media. Multimedia elements and retrieval systems in the leading Spanish online newspapers

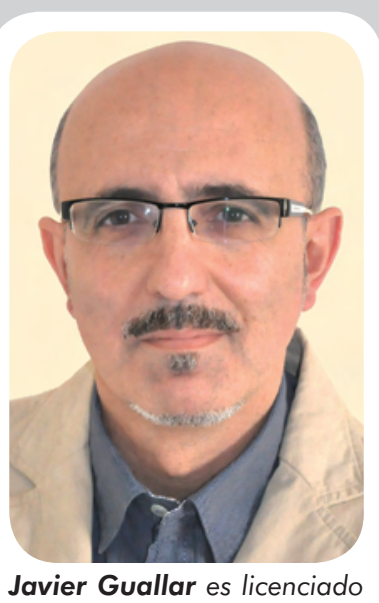
en geografía e historia por la UB, y en información y documentación por la UOC. Profesor de la Facultat de Biblioteconomia i Documentació de la Univ. de Barcelona y de la Facultat de Comunicació Blanquerna de la Univ. Ramon Llull. Es subdirector de El profesional de la información y coordinador del Anuario ThinkEPI.

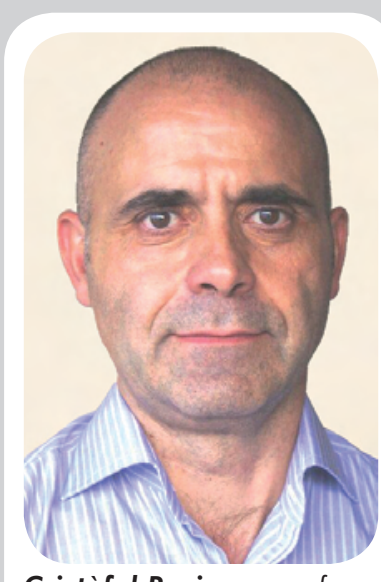

Cristòfol Rovira es profesor agregado del área de Biblioteconomía y Documentación de la Univ. Pompeu Fabra, donde imparte docencia en las titulaciones de Periodismo y Comunicación audiovisual, así como en el Máster online en documentación digital, Master en buscadores y en el Master UB/UPF de Gestión de contenidos digitales.

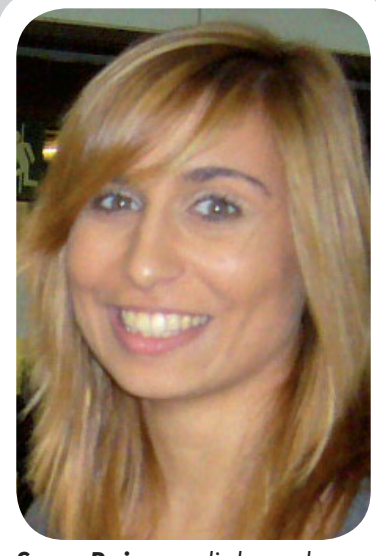

Sara Ruiz es diplomada en biblioteconomía y documentación y master en Gestión de contenidos digitales por la Universitat de Barcelona (UB). Actualmente cursa la licenciatura en documentación en la Universitat Oberta de Catalunya (UOC). Es documentalista del Departamento de Documentación de Televisión Española (TVE) de Catalunya en Sant Cugat.

Abstract: We show the results of a study about the presence of multimedia content in the leading Spanish online newspapers, over a period of six months (October 2009 to March 2010) and describe the search and retrieval systems for these contents. The main conclusions are: unequal presence of photography, video and graphics; stability and no increase in multimedia features for the period of the study, and differences in the quality of multimedia search.

Keywords: Online journalism, Online media, Digital media, Online newspapers, Multimedia, Photography, Video, Graphics, Search, Digital press archives.

Guallar, Javier; Rovira, Cristòfol; Ruiz, Sara. "Multimedialidad en la prensa digital. Elementos multimedia y sistemas de recuperación en los principales diarios digitales españoles". El profesional de la información, 2010, noviembre-diciembre, v. 19 , n. 6, pp. 620-629.

DOI: 10.3145/epi.2010.nov.08

\section{Introducción. La multimedialidad en los diarios digitales}

La multimedialidad se entiende en el contexto de la prensa digital como "la utilización conjunta de las formas básicas de información, es decir, texto, sonido, imagen fija y animada, en un mismo entorno, y de manera yuxtapuesta o integrada" (Abadal; Guallar, 2010, p. 42).
Es una de las características fundamentales de la prensa digital. Así queda de manifiesto en la bibliografía especializada, donde aparece siempre como un elemento esencial de los medios digitales, tanto si las características consideradas son tres (hipertextualidad, interactividad y multimedialidad: Deuze, 2003; Salaverría, 2004, 2005), cuatro (las anteriores más ruptura de la periodicidad o actualización, Díaz-Noci y Meso- 
Ayerdi, 1998), cinco (las tres primeras más personalización y memoria o documentación, Daltoé, 2003), seis (todas las anteriores: Canavilhas, 2007; Abadal y Guallar, 2010; Masip, 2010), o más (Zamith, 2008).

Ya en los primeros análisis que se hicieron sobre los nuevos diarios que aparecían en internet se destacaba esta característica como definitoria. Así Díaz-Noci señalaba en una fecha tan temprana como 1994 que el nuevo periodismo electrónico suponía la "redefinición del mensaje periodístico tradicional como producto interactivo y multimedia" (Díaz-Noci y Meso-Ayerdi, 1999, pp. 17-27).

\section{"La multimedialidad es una de las características fundamentales de la prensa digital"}

Si lo multimedia distingue y singulariza los diarios en internet de sus precedentes impresos, una de las claves de la evolución de los periódicos digitales en sus casi dos décadas de historia ha sido la progresiva superación del modelo de publicación deudor del medio impreso y la incorporación de un modelo propio, en el que en su etapa actual tiene una presencia destacada la multimedialidad.

Esta evolución se ha explicado por algunos autores en una serie sucesiva de fases. Cabrera-González (2001) distingue los modelos facsimilar (reproducción en internet del pdf de la edición impresa), adaptado (adaptación de los contenidos impresos al formato digital de manera muy elemental), digital (creación propia para el entorno de internet, con la utilización de las características antes señaladas) y finalmente, el digital multimedia (el sistema anterior con plena utilización de elementos multimedia), fase esta última que Abadal y Guallar (2010) denominan multimedia social (incorporación de contenidos multimedia y sociales).

Cronológicamente, si la adopción del modelo digital tiene lugar en los diarios más avanzados en los inicios de la década de 2000, el paso hacia el digital multimedia o multimedia social se sitúa a partir de mediados de esa misma década. Con todo, la secuencia de incorporación de los diferentes formatos no ha sido homogénea: primero fue la fotografía (que ya estaba presente prácticamente desde los orígenes de la prensa digital); después los gráficos (aunque solamente en algunos pocas cabeceras destacadas, como El mundo y El país); y a continuación el vídeo, hacia 2007, que fue considerado "el año del vídeo" (Guallar, 2008), mientras que el audio ha tenido hasta el momento una presencia más testimonial.

\section{Material y métodos}

\subsection{Antecedentes}

Los análisis sobre contenidos multimedia en diarios online aparecen en primer lugar en algunos estudios amplios que analizan las características del periodismo digital, como los de Van-der-Wurff y Lauf (2006) o Zamith (2008).

Los trabajos dedicados exclusivamente a la multimedialidad no son muy numerosos, pero en los últimos años han ido en aumento. Hay desde estudios sobre la presencia de varios formatos a análisis dedicados a uno de ellos. Se pueden citar sobre la fotografía en diarios digitales a Caminos-Marcet, Marín-Murillo y Armentia-Vizuete (2006), Sánchez-Vigil, Marcos-Recio y Villegas-Tovar (2007) y Villa (2008); sobre infografía a Valero (2003, 2004); sobre fotografía e infografía a Yuste, Sandoval y Franco (2006), y sobre vídeo a López-García (2008), Micó-Sanz y Masip (2008) y Masip (2010). Por último, Cabrera-González (2009) analiza el conjunto de elementos multimedia.

En cuanto a los sistemas de búsqueda de contenidos multimedia, se pueden señalar algunos trabajos sobre recuperación de la información en la prensa o sobre hemerotecas digitales que dedican indicadores de análisis a la búsqueda multimedia, como Guallar y Abadal (2009), López-Aguirre (2009), Martínez-Rubio (2008, 2010), y Camacho et al. (2010).

\subsection{Método}

El objetivo de este trabajo es analizar la presencia de contenidos multimedia en la prensa digital española en la actualidad, así como los sistemas existentes para su búsqueda y recuperación. Se trata de un análisis fundamentalmente cuantitativo, en el que no se han considerado aspectos cualitativos, como por ejemplo la autoría de dichos elementos.

Para ello se ha seleccionado una muestra representativa de los principales periódicos digitales españoles, sobre los que se han cuantificado los contenidos multimedia y su distribución en el sitio web (página de inicio, secciones, galerías), a lo largo de seis meses, y se han analizado los sistemas de búsqueda multimedia que presentan. A continuación se detalla más el procedimiento seguido.

El sistema de confección de la muestra de análisis es el seguido por uno de los autores en otros trabajos sobre diarios digitales (Guallar; Abadal, 2010). Está basado en la combinación de los datos de los dos principales sistemas de medición de audiencias en España, el Estudio general de medios (EGM) y OJD Interactiva. El motivo es que, como es sabido, algunos medios no están presentes en alguno de estos dos sistemas. Por 
ejemplo, El mundo no aparece en EGM y El país en OJD Interactiva.

http://www.aimc.es

http://www.ojdinteractiva.es/

Los diarios de mayor audiencia según datos disponibles a octubre de 2009 en EGM (consulta 14 de octubre de 2009) son Marca, El país, AS, El mundo deportivo, 20 minutos, Sport, La vanguardia, El periódico, Público, ABC, La voz de Galicia, El economista, El correo y Expansión. Por su parte, los de mayor audiencia en la misma fecha en OJD Interactiva son $\mathrm{El}$ mundo, Marca, 20 minutos, Sport, El mundo deportivo, La vanguardia, El periódico, El confidencial, Libertad digital, Expansión, La voz de Galicia, Público, Soitu y La nueva España.

Si juntamos los diez primeros resultados de cada lista se obtiene un nuevo listado de catorce diarios, que constituye la muestra de análisis de este trabajo. Estos son por orden alfabético:

20 minutos
http://www.20minutos.es
ABC
http://www.abc.es
AS
http://www.as.com
El confidencial
http://elconfidencial.com
El mundo
http://www.elmundo.es
El país
http://www.elpais.com

El periódico

http://www.elperiodico.com

Expansión

http://www.expansion.com

Libertad digital

http://www.libertaddigital.com

La vanguardia

http://www.lavanguardia.es

Marca

http://www.marca.com

Mundo deportivo

http://www.elmundodeportivo.es

Público

http://www.publico.es

Sport

http://www.sport.es

La muestra incluye nueve periódicos de información general y cinco de información especializada (4 deportivos y 1 económico).
El procedimiento de recogida de datos ha sido por observación de los sitios webs de los diarios.

Cada quince días entre el 13 de octubre de 2009 y el 16 de marzo de 2010, se han contabilizado los elementos multimedia de la página de inicio y de las secciones. Se ha excluido la publicidad y algunas imágenes que aparecen de manera permanente y están asociadas al diario, como las de los redactores.

Las secciones analizadas además de la página de inicio son: en los diarios generalistas, Internacional, Política y Sociedad, Opinión, Gente y televisión, Tecnología, Economía, Deportes y Otras; en los diarios deportivos, Fútbol, Motor, Baloncesto y Otras; en el diario económico Expansión las propias. No se han considerado las secciones de blogs (excepto los videoblogs, que sí se contabilizan como vídeos) u otras secciones de participación social. Se ha tenido en cuenta la página inicial de cada sección y no la sección completa.

En algunos casos se han agrupado las secciones reales en una sola de la clasificación anterior, para poder comparar mejor los resultados entre diferentes diarios. Por ejemplo en La vanguardia, Política, Ciudadanos y Sucesos se han agrupado en Política y Sociedad; Internet y Tecnología, en Tecnología; y Cultura se ha incluido en Otras.

Se han contabilizado los contenidos multimedia dos días al mes y se ha realizado una estimación mensual de la siguiente manera: Estimación mensual $=(x+y / 2)$ $\mathrm{dm}$, donde " $\mathrm{x}$ " son los datos recogidos el día de la primera quincena, "y" los del día de la segunda, y "dm" el número de días del mes.

Por su parte, los ítems de las galerías se han contabilizado dos veces, una al inicio del período de estudio en octubre de 2009, y otra al final en marzo de 2010. El análisis de las galerías se ha hecho solamente sobre los diarios que permitían la consulta por fecha, ya que de otra manera no es posible contabilizar el número de ítems.

Finalmente los sistemas de recuperación se han observado al final del período estudiado, en marzo de 2010. Para su análisis, se ha considerado una clasificación en tres niveles:

1. Nivel inferior. No existe ningún sistema de recuperación de contenido multimedia.

2. Nivel medio. Los sistemas de recuperación, por fecha o búsqueda por palabra clave, están situados en las galerías correspondientes.

3. Nivel avanzado. La búsqueda multimedia está integrada en el buscador o hemeroteca general del diario. 


\section{Resultados}

\subsection{Cuantificación de elementos multimedia}

La utilización de los diferentes formatos multimedia en la prensa digital española es muy dispar. La fotografía es el que tiene mayor presencia: hay catorce veces más fotografías que vídeos y veinte veces más que gráficos. A pesar de la fuerte irrupción en los últimos años del vídeo en la prensa digital, la fotografía continúa siendo el contenido multimedia predominante y de momento con mucha diferencia.

Por su parte el audio está presente en pocos diarios y cuando es así, se trata de ficheros que provienen de webs de radios pertenecientes

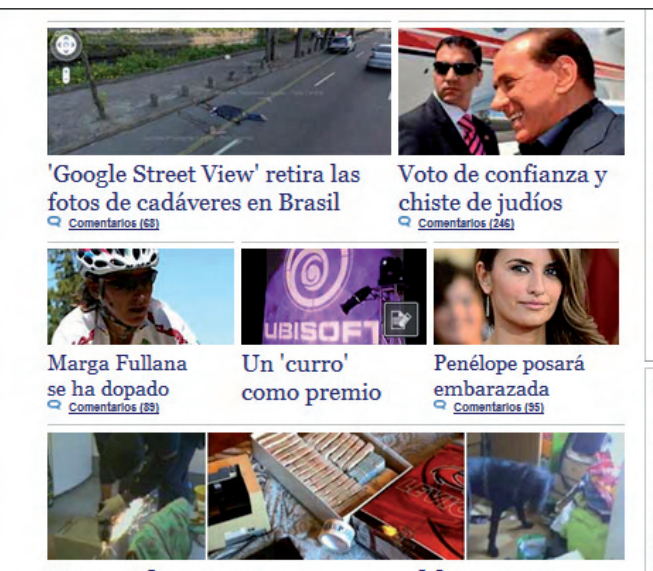

Detenidas 41 personas por blanquear dinero del narcotráfico para las FARC

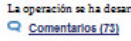

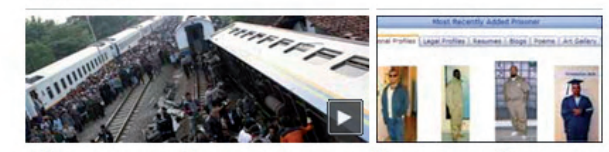

$\Delta \mathrm{l}$ mannc of muartac an Los presos tienen su

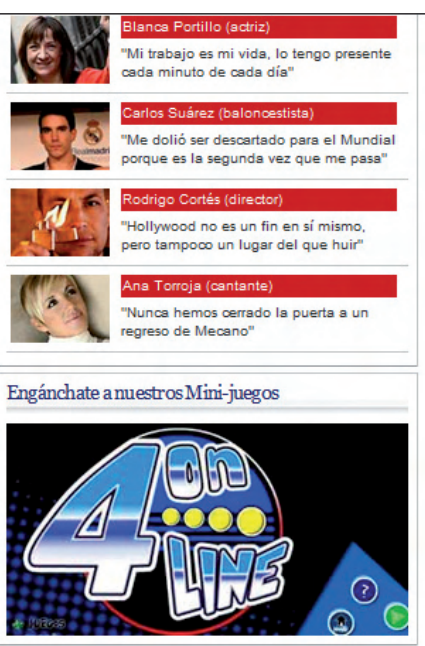

'2ominutos.es' enlas redes sociales

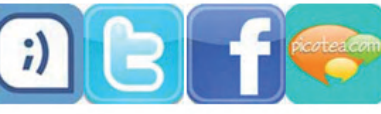

Figura 1. Utilización de fotografías en 20 minutos

a grupos empresariales periodísticos multimedia. Por ejemplo en $A S$ y El país se muestran audios de Cadena Ser, y en $A B C$ de Punto radio. Esta situación también ocurre en casos puntuales con los vídeos; sin embargo, en los audios se produce una masiva reutilización de elementos creados específicamente para ser emitidos en otros medios, generalmente en cadenas de radio del mismo grupo. En muchas ocasiones la activación de la audición desde el diario implica acceder a la sede web de la radio emisora. Por ello no se ha contabilizado el audio en este trabajo al considerar que requiere un estudio específico con mayor profundidad.

\section{"La fotografía es el formato multimedia predominante con mucha diferencia"}

\begin{tabular}{|l|r|r|r|}
\hline \multicolumn{1}{|c|}{ Diario } & Fotografía & Vídeo & Gráficos \\
\hline 20 minutos & 490,3 & 7,3 & 19,4 \\
\hline ABC & 193,2 & 22,6 & 1,3 \\
\hline El confidencial & 59,2 & 0,3 & 1,2 \\
\hline El mundo & 126,6 & 13,0 & 5,5 \\
\hline El país & 52,0 & 14,3 & 2,3 \\
\hline El periódico & 41,8 & 1,4 & 1,2 \\
\hline Vanguardia & 86,3 & 17,7 & 15,5 \\
\hline Libertad digital & 87,3 & 0,0 & 2,9 \\
\hline Público & 67,8 & 2,2 & 0,7 \\
\hline Expansión & 63,3 & 0,7 & 17,0 \\
\hline AS & 52,4 & 11,2 & 6,4 \\
\hline Marca & 93,9 & 10,8 & 3,2 \\
\hline Mundo deportivo & 42,7 & 4,4 & 4,7 \\
\hline Sport & 41,7 & 1,1 & 1,0 \\
\hline Promedio general & $\mathbf{1 0 7 , 1}$ & $\mathbf{7 , 6}$ & $\mathbf{5 , 9}$ \\
\hline
\end{tabular}

Tabla 1. Promedio diario de elementos multimedia
En algunas cabeceras la presencia multimedia está muy por encima del promedio general. Destaca especialmente 20 minutos (figura 1) con 490,3 fotografías y 19,4 gráficos diarios (4,5 y 3,3 veces el promedio respectivamente). Este número tan elevado de imágenes se explica tanto por la utilización intensiva de éstas como por el uso habitual de la repetición de unos mismos elementos durante diferentes días.

Por el contrario la cantidad de vídeos en Sport, Expansión, El confidencial y El periódico es escasa, con valores cercanos e inferiores a 1 vídeo diario. Estos datos contrastan con los de $A B C$ (figura 2) y La vanguardia con promedios de 22,6 y 17,7 vídeos publicados cada día. Los valores nulos en Libertad digital son debidos a la existencia de Libertad digital televisión, una sede web independiente del mismo grupo: en el periódico Libertad digital no hay vídeos que se descarguen en sus páginas, sino enlaces que conducen al

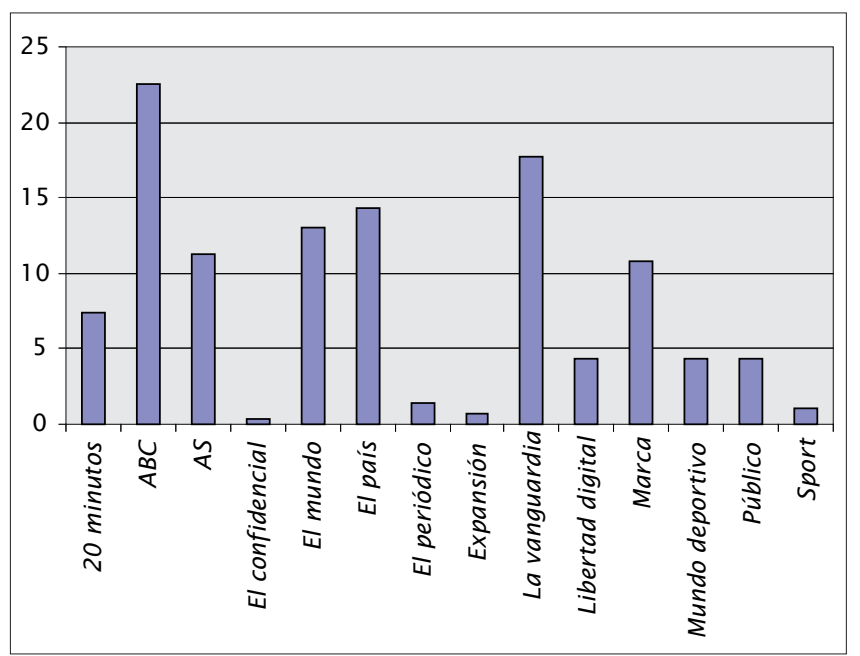

Gráfico 1. Promedio diario de vídeos 


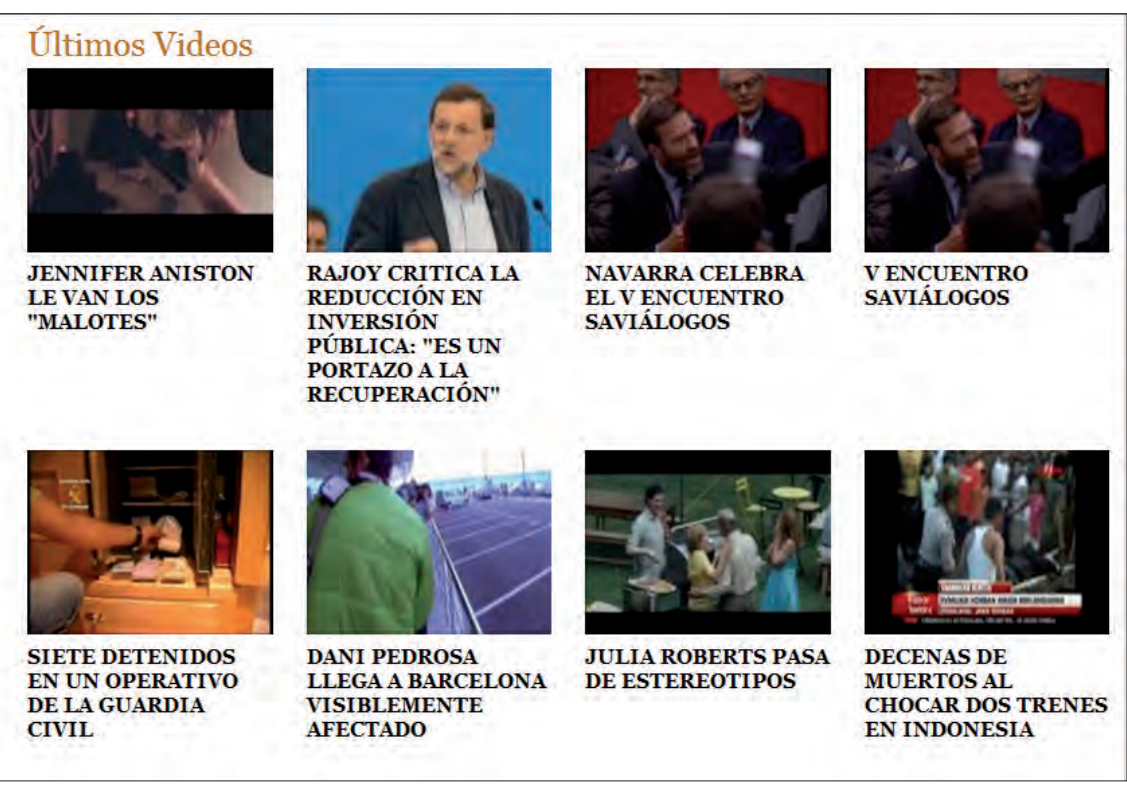

Figura 2. Vídeos del día en $A B C$

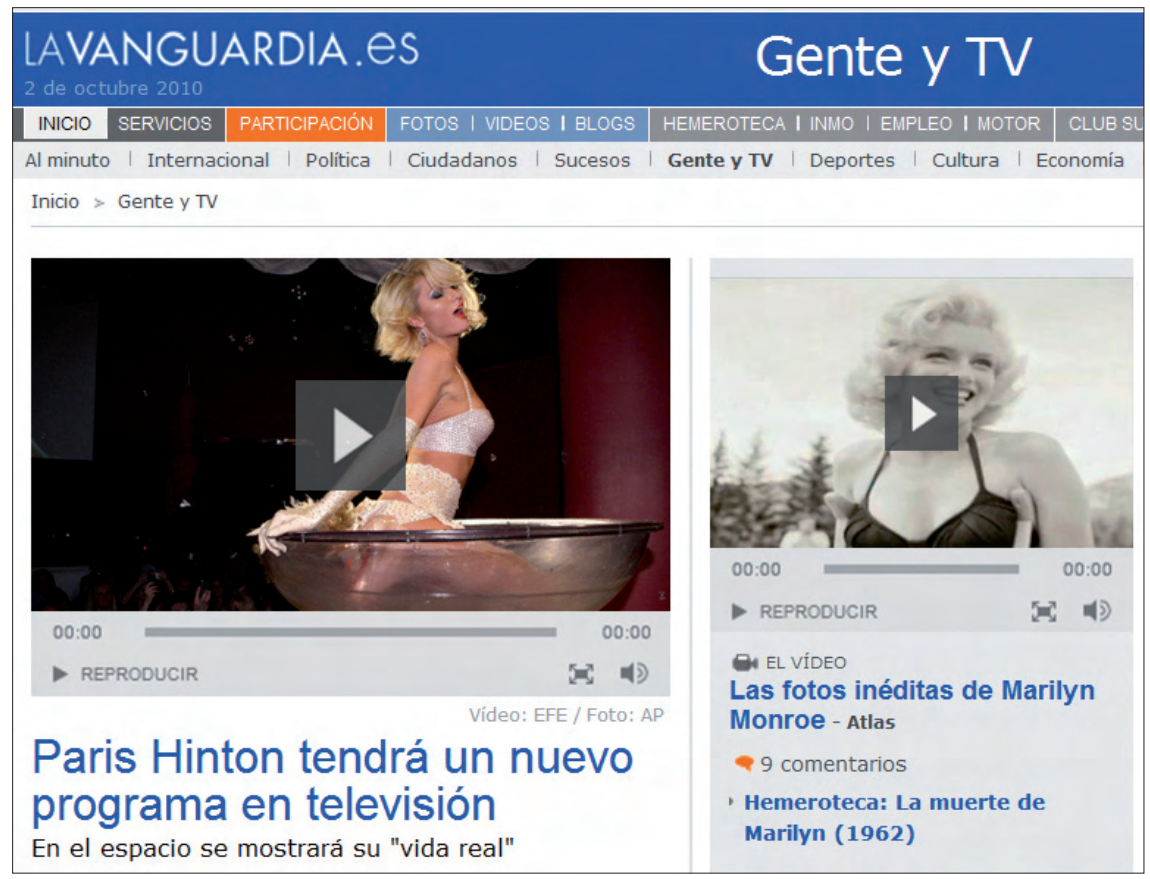

Figura 3. Vídeos en la sección Gente/TV en La vanguardia

portal dedicado en exclusiva a la televisión online.

\subsection{Análisis por secciones}

En los medios generalistas destaca la alta presencia multimedia en la home, Deportes y Gente/TV (figura 3). En cambio en Opinión, como cabría esperar, la multimedialidad es muy escasa, diez veces menos que en la home (17,8 y 188,5 elementos multimedia en total respectivamente en los 6 meses de estudio).

"En los diarios generalistas la presencia multimedia es alta en la home, Deportes y Gente/TV, y escasa en la sección de Opinión"

En los diarios deportivos se observa igualmente una alta utilización de contenidos multimedia en la home, y sorprende el mayor uso multimedia en Motor que en Fútbol, deporte al que se dedica mayor atención. También es sorprendente la ausencia total de gráficos en la sección de Baloncesto.

\subsection{Galerías}

Los periódicos tienen en muchos casos secciones dedicadas en exclusiva a alguno de los formatos multimedia, en especial a fotografías o vídeos. Son las llamadas galerías, que también se pueden denominar según el formato: videotecas, fototecas, videogalerías o fotogalerías.

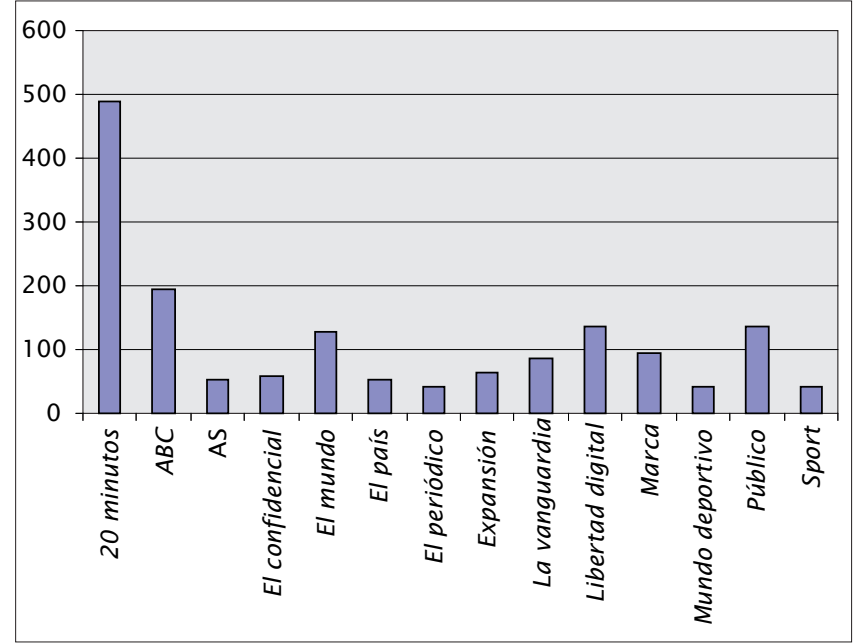

Gráfico 2. Promedio diario de fotografías

\begin{tabular}{|l|r|r|r|r|}
\hline \multicolumn{1}{|c|}{ Sección } & Fotografía & Vídeo & Gráficos & \multicolumn{1}{c|}{ Total } \\
\hline Home & 171,1 & 11,7 & 5,7 & 188,6 \\
\hline Política y sociedad & 130,8 & 13,7 & 4,2 & 148,7 \\
\hline Internacional & 55,1 & 3,2 & 1,0 & 59,3 \\
\hline Opinión & 15,5 & 2,3 & 0,0 & 17,8 \\
\hline Gente/TVE & 165,4 & 10,6 & 5,8 & 181,7 \\
\hline Tecnología & 144,7 & 10,3 & 3,9 & 158,9 \\
\hline Economía & 43,5 & 4,3 & 9,9 & 57,7 \\
\hline Deportes & 158,7 & 7,5 & 13,2 & 179,4 \\
\hline Otros & 308,8 & 15,2 & 6,1 & 330,1 \\
\hline Total & $\mathbf{1 . 1 9 3 , 6}$ & $\mathbf{7 8 , 9}$ & $\mathbf{4 9 , 8}$ & $\mathbf{1 . 3 2 2 , 2}$ \\
\hline
\end{tabular}

Tabla 2. Promedio multimedia diario en las páginas iniciales de las secciones 
Como se ha indicado antes, para poder contabilizar los ítems se han analizado los medios que permiten la consulta de las galerías por fecha: son siete en cuanto a

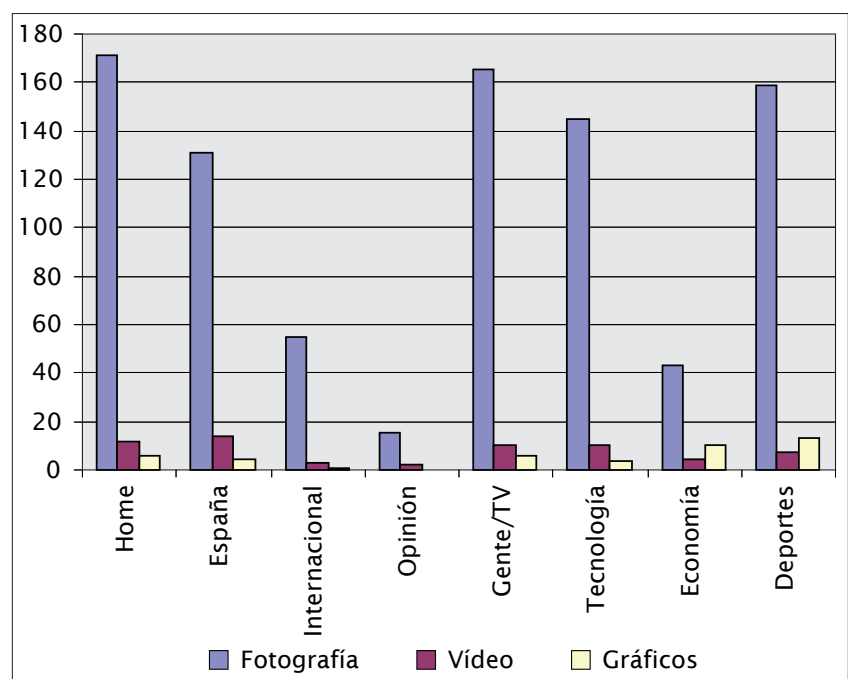

Gráfico 3. Promedio multimedia diario en las páginas iniciales de las secciones en diarios generalistas

\begin{tabular}{|l|c|c|c|c|}
\hline \multicolumn{1}{|c|}{ Sección } & Fotografía & Vídeo & Gráficos & Total \\
\hline Home & 59,1 & 11,5 & 5,0 & 75,7 \\
\hline Fútbol & 36,4 & 2,3 & 4,0 & 42,7 \\
\hline Motor & 39,4 & 3,2 & 2,9 & 45,4 \\
\hline Baloncesto & 20,8 & 3,3 & 0,0 & 24,0 \\
\hline Otros deportes & 75,2 & 7,2 & 3,4 & 85,7 \\
\hline Total & $\mathbf{2 3 0 , 8}$ & $\mathbf{2 7 , 5}$ & $\mathbf{1 5 , 3}$ & $\mathbf{2 7 3 , 5}$ \\
\hline
\end{tabular}

Tabla 3. Promedio multimedia diario en las páginas iniciales de las secciones

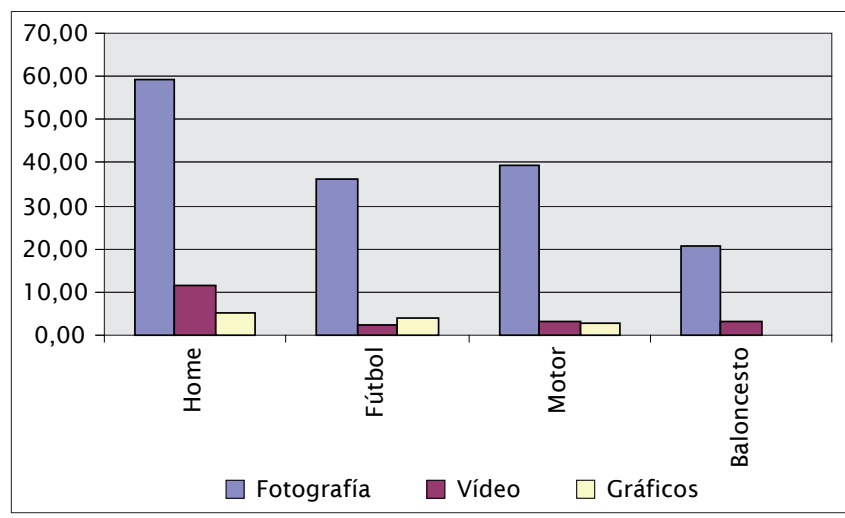

Gráfico 4. Promedio multimedia diario en las páginas iniciales de las secciones en diarios deportivos

\begin{tabular}{|l|r|r|r|r|r|}
\hline \multicolumn{1}{|c|}{ Diario } & \multicolumn{1}{c|}{$\begin{array}{c}\mathbf{1 0 /} \\
\mathbf{2 0 0 9}\end{array}$} & $\begin{array}{c}\mathbf{0 3 /} \\
\mathbf{2 0 1 0}\end{array}$ & $\begin{array}{c}\text { Pro- } \\
\text { medio }\end{array}$ & $\begin{array}{c}\text { Dife- } \\
\text { rencia }\end{array}$ & $\begin{array}{c}\text { \% dife- } \\
\text { rencia }\end{array}$ \\
\hline AS & 344 & 435 & 390 & 91 & 26,5 \\
\hline El mundo & 5.352 & 4.550 & 4.951 & -802 & $-15,0$ \\
\hline El país & 523 & 1.722 & 1.123 & 1199 & 229,3 \\
\hline La vanguardia & 1.300 & 1.178 & 1.239 & -122 & $-9,4$ \\
\hline Libertad digital & 330 & 690 & 510 & 360 & 109,1 \\
\hline Mundo deportivo & 1.421 & 1.207 & 1.314 & -214 & $-15,1$ \\
\hline Sport & 459 & 415 & 437 & -44 & $-9,6$ \\
\hline Promedio & $\mathbf{1 . 3 9 0}$ & $\mathbf{1 . 4 5 7}$ & $\mathbf{1 . 4 2 3}$ & $\mathbf{6 7}$ & $\mathbf{4 , 8}$ \\
\hline
\end{tabular}

Tabla 4. Número de ítems en las fototecas fotos, y seis de vídeos. También existen en algunos diarios galerías de gráficos; no obstante entre los estudiados tan sólo El país incluía esta prestación al inicio del período de estudio (octubre 2009) y aunque con posterioridad otros cabeceras de la muestra la han incorporado (AS, Expansión, El mundo deportivo, Marca), no se ha podido realizar el análisis comparativo.

Tal como se ha indicado, hubo dos recogidas de datos, una al principio de la investigación (octubre 2009) y la otra a los seis meses (marzo 2010).

En el período estudiado El mundo (figura 4) es el periódico con mayor número de fotografías en su fotogalería y con mucha diferencia en relación con los otros medios, más de tres veces el promedio. Por otra parte se detecta en El país y en Libertad digital un aumento significativo del número de ítems entre las dos tomas de datos, con un $229 \%$ y $109 \%$ respectivamente. No obstante, no es una tendencia general ya que en valores globales sólo hubo un aumento del 4,8\%.

Tampoco aumenta de forma apreciable el número de ítems multimedia en las páginas iniciales de las secciones de los periódicos, apartado analizado en puntos anteriores. Comparando los datos estimados globales del primer y el último mes de recogida de datos podemos ver que en total hay una ligera disminución del $6 \%$. Tan sólo en el caso de vídeos y en el intervalo de enero a febrero se observa un aumento importante del $28 \%$, no obstante es un valor aislado que no marca tendencia.

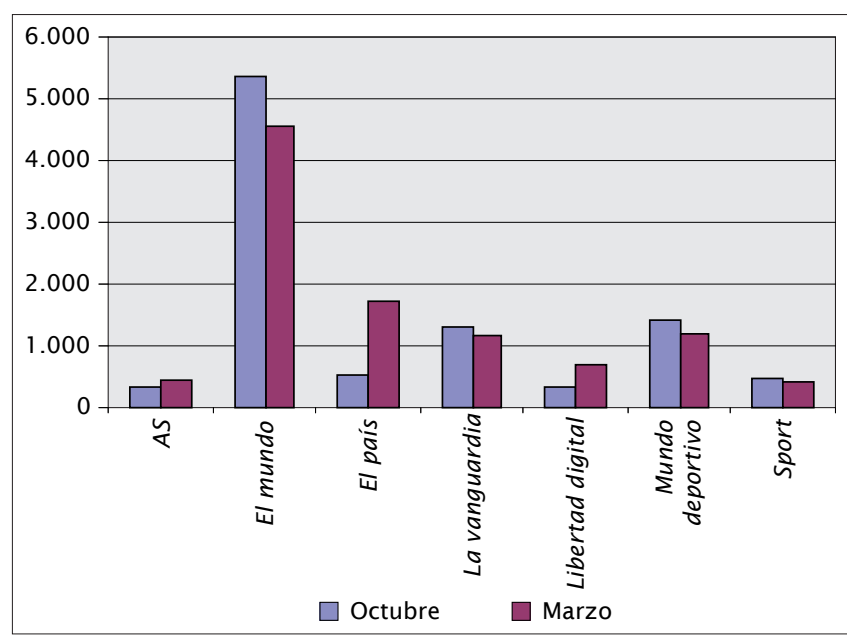

Gráfico 5. Número de ítems en las fototecas

\begin{tabular}{|l|c|c|c|c|}
\hline \multicolumn{1}{|c|}{ Intervalos } & $\begin{array}{c}\% \\
\text { fotografía }\end{array}$ & $\begin{array}{c}\% \\
\text { vídeo }\end{array}$ & $\begin{array}{c}\% \\
\text { gráficos }\end{array}$ & $\begin{array}{c}\% \\
\text { total }\end{array}$ \\
\hline Octubre-noviembre & 4 & -6 & 10 & 4 \\
\hline Noviembre-diciembre & -4 & -4 & 4 & -3 \\
\hline Diciembre-enero & -5 & 4 & -8 & -4 \\
\hline Enero-febrero & 6 & 28 & 11 & 8 \\
\hline Febrero-marzo & -10 & -5 & -11 & -9 \\
\hline Total octubre-marzo & $\mathbf{- 8}$ & $\mathbf{1 4}$ & $\mathbf{5}$ & $\mathbf{- 6}$ \\
\hline
\end{tabular}

Tabla 5. Variación del número de elementos multimedia en las páginas principales de las secciones (octubre 2009-marzo 2010) 


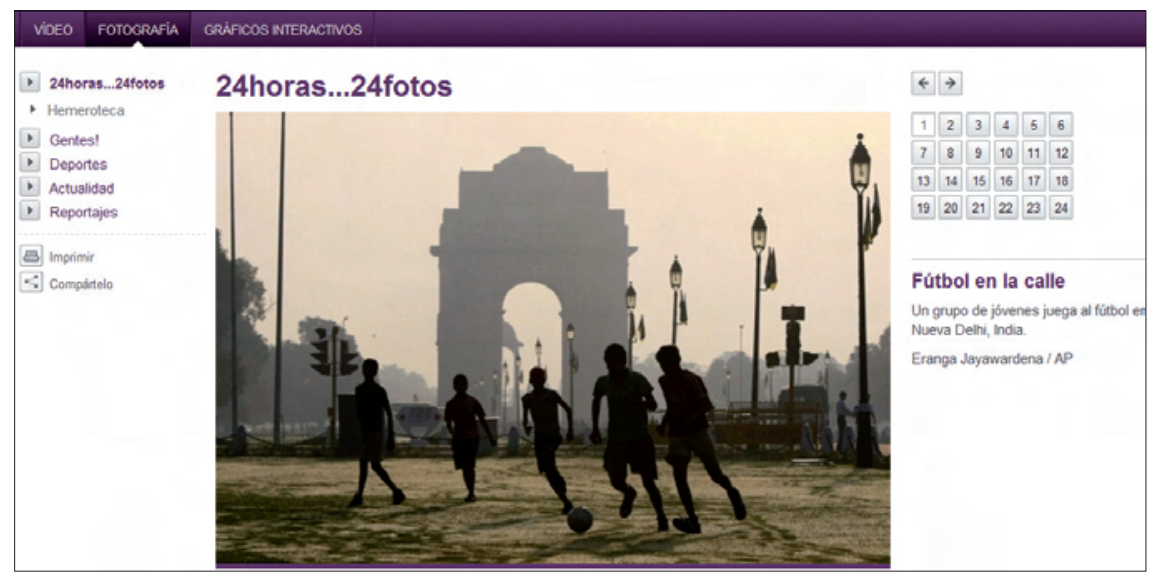

Figura 4. Galería de fotografías en El mundo

En cuanto a las videotecas, $A B C$ es el diario que ofrece un mayor número de vídeos, igualmente con mucha diferencia en relación con los otros medios estudiados, con más de cuatro veces el promedio. También cabe destacar la importante reducción del número de

\section{"Las galerías son secciones dedicadas en exclusiva a alguno de los elementos multimedia, en especial a fotografías o vídeos"}

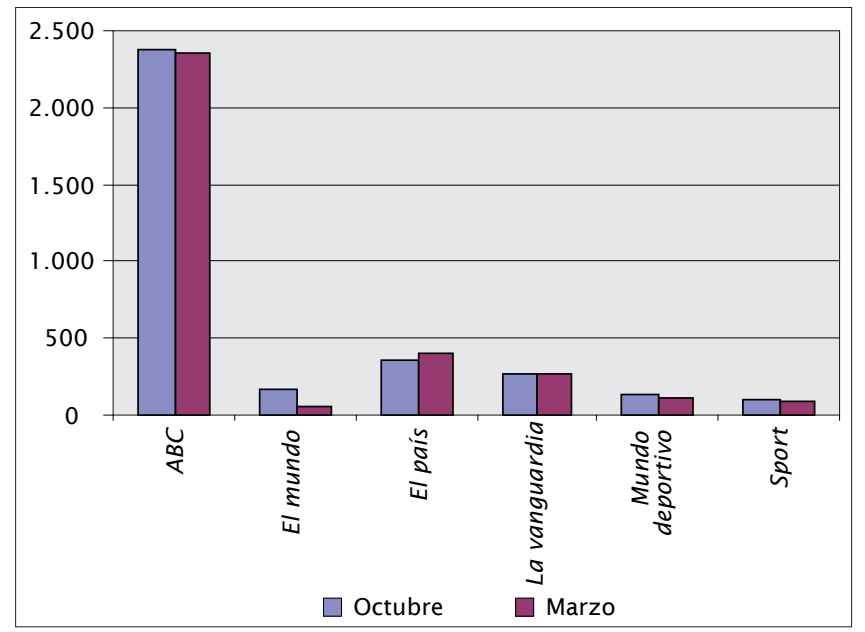

Gráfico 6. Número de ítems en las videotecas

\begin{tabular}{|l|r|r|r|r|c|}
\hline \multicolumn{1}{|c|}{ Diario } & $\begin{array}{c}\text { Octu- } \\
\text { bre }\end{array}$ & Marzo & $\begin{array}{c}\text { Prome- } \\
\text { dio }\end{array}$ & $\begin{array}{c}\text { Diferen- } \\
\text { cia }\end{array}$ & $\begin{array}{c}\text { \% dife- } \\
\text { rencia }\end{array}$ \\
\hline ABC & 2.376 & 2.360 & $2.368,0$ & -16 & $-0,7$ \\
\hline El mundo & 165 & 60 & 112,5 & -105 & $-63,6$ \\
\hline El país & 357 & 400 & 378,5 & 43 & 12,0 \\
\hline $\begin{array}{l}\text { La vanguar- } \\
\text { dia }\end{array}$ & 266 & 272 & 269,0 & 6 & 2,3 \\
\hline $\begin{array}{l}\text { Mundo de- } \\
\text { portivo }\end{array}$ & 130 & 111 & 120,5 & -19 & $-14,6$ \\
\hline Sport & 106 & 88 & 97,0 & -18 & $-17,0$ \\
\hline Promedio & $\mathbf{5 6 7}$ & $\mathbf{5 4 9}$ & $\mathbf{5 5 8 , 0}$ & $\mathbf{- 1 8}$ & $\mathbf{- 3 , 2}$ \\
\hline
\end{tabular}

Tabla 6. Número de ítems en las videotecas vídeos en El mundo, con una disminución del $63,6 \%$ entre las dos tomas de datos. Tampoco en este caso es una tendencia general donde obtenemos tan sólo un 3,2\% de disminución. En general el número de vídeos permanece constante y por tanto aquí se puede deducir que se lleva a cabo un proceso de eliminación de ítems.

\subsection{Sistema de recuperación}

El último elemento de análisis fueron las interfaces de recuperación de información multimedia. Tal como se ha detallado en el apartado de metodología, se establecieron tres niveles de complejidad creciente.

Los resultados (tabla 7) muestran una fuerte polaridad. Casi la mitad de los diarios analizados (42\%) no tiene ningún sistema de recuperación (nivel 1) de contenidos multimedia. Por otra parte, la mitad exacta $(50 \%)$ tiene un sistema de calidad alta, integrando la búsqueda de formatos multimedia en el buscador o la hemeroteca general (nivel 3).

Cabe destacar el diseño de $E l$ país que ofrece un doble sistema de consulta: una específica en la sección Multimedia para la búsqueda por los diferentes formatos; y la posibilidad de configurar el buscador general para limitar la búsqueda a contenidos multimedia (figura 5).

\section{"Casi la mitad de los diarios analizados no tiene ningún sistema de recuperación de contenidos multimedia"}

\begin{tabular}{|l|c|}
\hline \multicolumn{1}{|c|}{ Diario } & Nivel \\
\hline 20 minutos & 1 \\
\hline AS & 1 \\
\hline Confidencial & 1 \\
\hline El periódico & 1 \\
\hline Expansión & 1 \\
\hline Libertad digital & 1 \\
\hline Público & 2 \\
\hline El país & 2 y 3 \\
\hline ABC & 3 \\
\hline El mundo & 3 \\
\hline La vanguardia & 3 \\
\hline Marca & 3 \\
\hline Mundo deportivo & 3 \\
\hline Sport & 3 \\
\hline
\end{tabular}

Tabla 7. Calidad del sistema de recuperación de información en las galerías de los principales diarios digitales españoles 


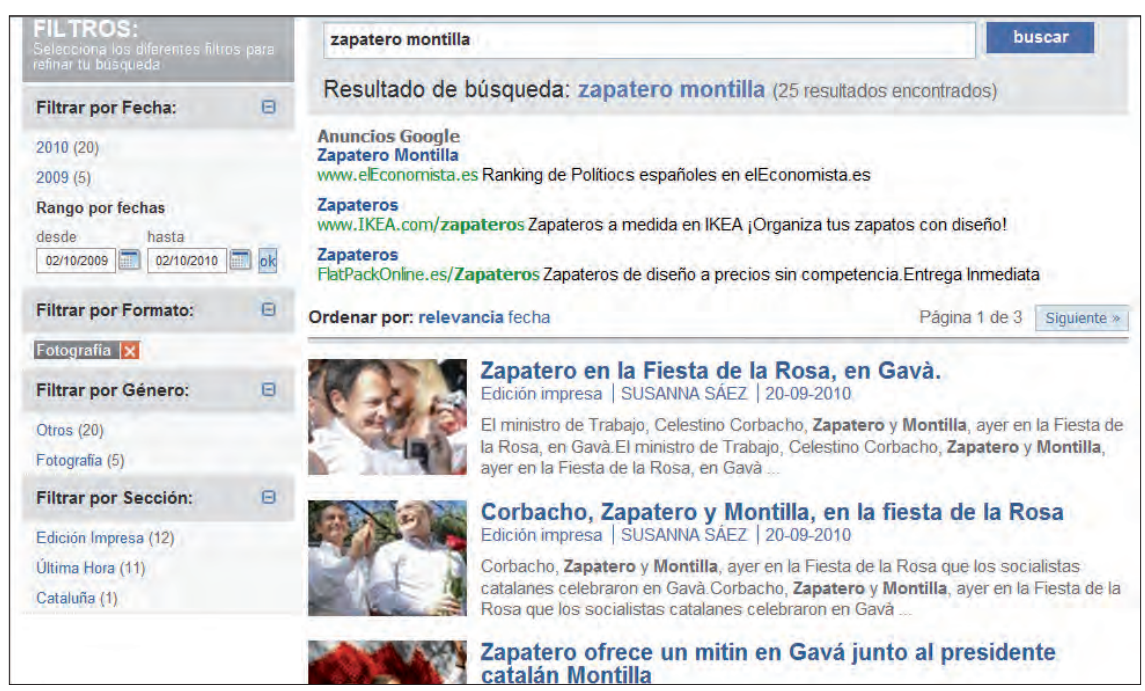

Figura 5. Búsqueda de fotografías integrada en el buscador general del diario El país de la edición papel sino también unos nuevos gráficos interactivos con la utilización de otros formatos, que constituyen una importante aportación de la prensa digital. Sin embargo al nivel cuantitativo de nuestro estudio la presencia de gráficos es sensiblemente inferior a los otros dos formatos. También queda de manifiesto esto en las galerías, que son mayoritariamente de fotografías y de vídeos, y menos frecuentes de gráficos.

Por último, en lo que se refiere al audio se ha constatado la reutilización por parte de los diarios de contenidos de cadenas de radio afi-

\section{Conclusiones}

Del análisis de los resultados obtenidos se proponen las siguientes conclusiones como elementos para la discusión:

\section{Desigual presencia de formatos multimedia}

La presencia de los diferentes formatos multimedia en los diarios digitales es muy desigual. Destaca la utilización de fotografías, que es muy superior a los otros formatos.

La fotografía sigue siendo por tanto fundamental en el periodismo digital, como lo ha sido siempre en el impreso. En la Web no existen las limitaciones de espacio de unas páginas determinadas como en la prensa impresa, por lo que las fotografías llenan las ediciones digitales de los diarios, y ya no solamente junto al texto de las informaciones, sino en galerías de imágenes diferenciadas del texto, dispuestas temática o cronológicamente.

Los diarios digitales suelen presentar de manera generalizada dos formatos multimedia más entre sus contenidos: los vídeos y los gráficos, aunque a una considerable distancia de las fotografías. Los primeros irrumpieron con fuerza en la prensa digital y se han estabilizado. No es un formato existente en la prensa de papel, sino que antes de internet se identificaba con otro medio de comunicación distinto al diario, como es la televisión. No todos los periódicos tienen vídeos entre sus contenidos, pero en la muestra estudiada (los de mayor audiencia) sí que es notable su presencia. Se pueden presentar también, como en el caso de las fotografías, en galerías.

De los gráficos se puede señalar que ya existen y son relevantes en la prensa impresa (especialmente en las grandes cabeceras), si bien el entorno digital permite realizar no solamente los gráficos estáticos propios nes, por lo que se ha optado por excluir su cuantificación de esta investigación y remitir a futuros estudios específicos.

\section{"No hay una evolución al alza del número de contenidos multimedia durante los seis meses del estudio"}

\section{Estabilidad y no crecimiento de elementos multime- dia}

No se ha detectado una evolución al alza del número de contenidos multimedia durante los seis meses del estudio. Hay una gran estabilidad en ese período. Estos datos pueden sorprender de entrada, pues se podría pensar que la multimedialidad en los diarios, dada su relativa novedad, debería ir en aumento. No es así, y esta estabilidad en la cantidad de información multimedia se puede interpretar como una consolidación de un cierto modelo de diario en lo que se refiere a la utilización de lo multimedia, en base a:

a) determinadas características de distribución de los diferentes formatos (que se han señalado en el punto anterior);

b) cierto número de elementos, que se mantiene bastante estable.

Dicho de otra manera, los medios estudiados, salvo las matizaciones expuestas en el apartado de resultados, han mantenido un mismo tipo de periódico en el período analizado, de octubre de 2009 a marzo de 2010 , sin cambios importantes. 


\section{Diferencias en la búsqueda multimedia}

Aproximadamente la mitad de los medios analizados ofrecen un sistema de búsqueda multimedia de calidad alta integrado en las prestaciones del buscador o hemeroteca general del diario; mientras que la otra mitad en cambio no tienen ningún sistema de recuperación multimedia. Esta desigualdad, casi al 50\%, marca una diferencia entre aquellos diarios que valoran de manera importante la recuperación de contenidos multimedia y aquellos otros que todavía no lo hacen. A falta de otros datos, sería de esperar en el futuro una progresión de los diarios que todavía presentan un nivel bajo en este apartado.

\section{Elementos individuales a destacar}

Sobre las tendencias generales hasta ahora señaladas sobresalen algunos elementos individuales:

- 20 minutos destaca por el número de fotografías;

- ABC y La vanguardia son los diarios digitales con mayor número de vídeos;

- La página de inicio, Deportes y Gente/TV son las secciones con mayor utilización de lo multimedia;

- El mundo destaca por la gran cantidad de ítems en su fotogalería y $A B C$ en su videoteca;

- El país tiene un doble sistema de búsqueda multimedia: en las galerías e integrado en el buscador general.

\section{Limitaciones y futuros estudios}

Se han constatado algunas limitaciones en esta investigación, que se señalan a continuación para su consideración en posibles estudios futuros.

En primer lugar cabe hablar de la exclusión del audio en este análisis cuantitativo, por los motivos ya explicados. Se considera que será necesario realizar estudios específicos en el futuro, y no solamente cuantitativos, para analizar la política de los diarios respecto a la información en este formato.

En segundo lugar se debe señalar la dificultad para contabilizar los ítems de las galerías y de las secciones en algunos diarios, que impide estudiar cuantitativamente de manera totalmente satisfactoria ambos elementos. En el caso de las secciones, las agrupaciones efectuadas para comparar los resultados entre diarios no siempre son satisfactorias, ya que los ítems (noticias) que un diario considera en una sección pueden formar parte de otra diferente en otro diario. En este sentido, los resultados obtenidos son orientativos, muestran un panorama aproximado, y se deben manejar con precaución.

Por último, un estudio longitudinal como éste realizado a lo largo de seis meses, debe poderse contrastar con otros trabajos sobre períodos temporales más largos y/o posteriores.

Asimismo y como reflexión final aplicada al ámbito de los diarios digitales, se considera que los análisis cuantitativos ofrecen una descripción que es útil como aproximación al fenómeno a estudiar, pero se deben complementar con métodos cualitativos para obtener un análisis más ajustado del objeto estudiado.

\section{Nota}

Esta investigación ha sido desarrollada parcialmente en el contexto del trabajo final del Master en Gestión de Contenidos Digitales (UB-UPF) realizado por Sara Ruiz y ha sido financiada parcialmente por el proyecto CSO 2008-0262 del Ministerio de Ciencia e Innovación.

\section{Bibliografía citada}

Abadal, Ernest; Guallar, Javier. Prensa digital y bibliotecas. Gijón: Trea, 2010, 176 p. ISBN: 9788494462.

Cabrera-González, María-Ángeles. "Convivencia de la prensa escrita y la prensa on line en su transición hacia el modelo de comunicación multimedia". Estudios sobre el mensaje periodístico, 2001, n. 7, pp. 71-78.

http://www.ucm.es/info/perioI/Period_I/EMP/Numer_07/7-4-Comu/7-401.htm

Cabrera-González, María-Ángeles. "El diseño de la prensa digital española en el contexto de la convergencia tecnológica. La identidad visual del ciberperiodismo". Revista latina de comunicación social, 2009, n. 64, pp. 766-786. http://www.revistalatinacs.org/09/art/860_UMA/61_90_MA_Cabrera.html

Camacho, Idoia; Agirreazaldegi, Teresa; Ronco, Milagros; Peñafiel, Carmen. "¿Evolución o revolución?: adaptación de los servicios de documentación a la era digital". II Congreso intl de la Asociación Española de Investigadores de la Comunicación (AE-IC), Málaga, 3-5 febrero 2010. http://www.aeic2010malaga.org/upload/ok/243.pdf

Caminos-Marcet, José-María; Marín-Murillo, Flora; Armentia-Vizuete, José-Ignacio. "El uso de la fotografía en los diarios digitales españoles". Comunicación y sociedad, 2006, v. 19, n. 2, pp. 9-38.

Canavilhas, João. Webnoticia. Propuesta de modelo periodístico para la www. Covilhà: Livros Labcom, 2007.

Daltoé, Andrelise. "Promessas, desafios e ameaças das tecnologias digitais". Bocc, 2003.

http://www.bocc.ubi.pt/pag/daltoe-andrelise-promessas-desafios-tecnolo gias-digitais.pdf

Deuze, Mark. "The web and its journalisms: considering the consequences of different types of newsmedia online". New media \& society, 2003, v. 5, n. 2, p. 203-230.

Díaz-Noci, Javier. "Multimedia y modalidades de lectura: una aproximación al estado de la cuestión”. Comunicar, 2009, v. 12, n. 33, pp. 213-219. http://redalyc.uaemex.mx/pdf/158/15812486025.pdf

Díaz-Noci, Javier; Meso-Ayerdi, Koldo. "Desarrollo del periodismo electrónico". El profesional de la información, 1998, v. 7, n. 12, pp. 4-11. http://www.elprofesionaldelainformacion.com/contenidos/1998/diciembre/ desarrollo_del_periodismo_electronico.html

Díaz-Noci, Javier; Meso-Ayerdi, Koldo. Periodismo en internet: modelos de la prensa digital. Universidad del País Vasco. Servicio editorial: Bilbao, 1999, $120 \mathrm{p}$.

Guallar, Javier. "Prensa digital en 2007". Anuario ThinkEPI, 2008, v. 2, pp. 102-108.

http://eprints.rclis.org/16288/1/anuariothinkepi08_guallar_prensa-digital2007.pdf

Guallar, Javier; Abadal, Ernest. "Evaluación de hemerotecas de prensa digital: indicadores y ejemplos de buenas prácticas". El profesional de la información, 2009, mayo-junio, v. 18, n. 3, pp. 255-269.

http://eprints.rclis.org/16899/1/epi09_guallar-abadal_evaluacion_ hemerotecas.pdf 
Guallar, Javier; Abadal, Ernest. "The digital press archives of the leading Spanish online newspapers". Information research, 2010, v. 15, n. 1. http://informationr.net/ir/15-1/paper424.html

López-Aguirre, José-Luis. "Estudio de servicios y productos ciberdocumentales en la prensa digital mexicana". Documentación en ciencias de la información, 2009, v. 32, pp. 93-132.

http://revistas.ucm.es/inf/02104210/articulos/DCIN0909110093A.PDF

López-García, Guillermo. "La eclosión del vídeo como mecanismo de comunicación política en internet”. En: Congreso fundacional de la Asociación Española de Investigadores de la Comunicación. Santiago de Compostela, 2008

Martínez-Rubio, Rosa. "Estructura de la información y su recuperación en los diarios digitales andaluces: anàlisis de las vías de comunicación interna". En: II Congreso intl de la Asociación Española de Investigadores de la Comunicación (AE-IC). Málaga, 3-5 febrero 2010. http://www.aeic2010malaga.org/upload/ok/443.pdf

Martínez-Rubio, Rosa. "La recuperación de la información en los periódicos digitales valencianos". En: López-García, Guillermo (ed.). Сomunicación local y nuevos formatos periodísticos en internet: cibermedios, confidenciales y weblogs. Valencia: Servei de Publicacions de la Universita de València, 2008, pp. 99-140.

http://www.cibermediosvalencianos.es/comloc/Martinez.pdf

Masip, Pere. "El vídeo en los cibermedios: algunas certezas y muchas dudas". Anuario ThinkEPI, 2010, v. 4, pp. 180-185.

http://www.thinkepi.net/el-video-en-los-cibermedios-algunas-certezas-ymuchas-dudas

Micó-Sanz, Josep-Lluís; Masip, Pere. "Recursos multimedia en los cibermedios españoles”. Trípodos, 2008, n. 23, pp. 89-105.

http://www.raco.cat/index.php/Tripodos/article/view/118914/154118

Salaverría, Ramón. "Aproximación al concepto de multimedia desde los planos comunicativos e instrumental". Estudios sobre el mensaje periodís tico, 2001, n. 7, pp. 383-395.

http://hdl.handle.net/10171/5068

Salaverría, Ramón. "Diseñando el lenguaje para el ciberperiodismo". Chasqui, 2004, n. 86.

http://chasqui.comunica.org/content/view/102/72/

Salaverría, Ramón. Redacción periodística en internet. Pamplona: Eunsa, 2005 .
Sánchez-Vigil, Juan-Miguel; Marcos-Recio, Juan-Carlos; Villegas-Tovar, Ricardo. "Los recursos fotográficos en los periódicos digitales: valores de la fotografía digital". En: Ibersid 2007, pp. 211-218.

http://ibersid.eu/ojs/index.php/ibersid/article/download/3298/3059

Valero, José-Luis. "El relato en la infografía digital”. En: Díaz-Noci, Javier; Salaverría, Ramón. Manual de redacción ciberperiodística. Barcelona: Ariel, 2003, pp. 555-587.

Valero, José-Luis. "La infografía digital en el comienzo de una nueva manera de informar". En: I Congreso de periodismo digital, Maracay, 2004

http://www.analitica.com/media/9399701.pdf

Van-der-Wurff, Richard; Lauf, Edmund (eds). Print and online newspapers in Europe: a comparative content analysis in 16 countries in Western and Eastern Europe. Amsterdam: Het Spinhuis, 2005

Villa, Isabel. "Particularidades de la fotografía informativa en los medios on-line españoles". Revista latina de comunicación social, 2008, n. 63, pp. 303-312.

http://www.revistalatinacs.org/08/25_37_UAB/latina_art769.pdf

Yuste, Bárbara; Sandoval, María-Teresa; Franco, Guillermina. "Uso de la fotografía y la infografía en los periódicos digitales". En: III Congreso on-line observatorio para la cibersociedad, 2006.

http://www.cibersociedad.net/congres2006/gts/comunicacio.php?id=997

Zamith, Fernando. "A methodological proposal to analyze the news websites use of the potentialities of the internet". En: 9th International symposium on online journalism, University of Texas at Austin, April 5, 2008. http://online.journalism.utexas.edu/2008/papers/Zamith.pdf

Javier Guallar, Universitat de Barcelona. jguallar@gmail.com

Cristòfol Rovira, Universitat Pompeu Fabra. Barcelona.

cristofol.rovira@upf.edu

Sara Ruiz, TVE, Sant Cugat del Vallès (Barcelona). ladyoliva@gmail.com

\section{Spanish Meeting Point}

La revista El profesional de la información organiza una nueva edición del Spanish Meeting Point, dentro de la Online Information Conference, en Londres - la más importante del mundo en materia de contenidos y bases de datos científicas y profesionales, así como en software de gestión de contenidos.

\section{Online Information Conference, Londres 30 noviembre - 2 diciembre 2010}

http://www.online-information.co.uk

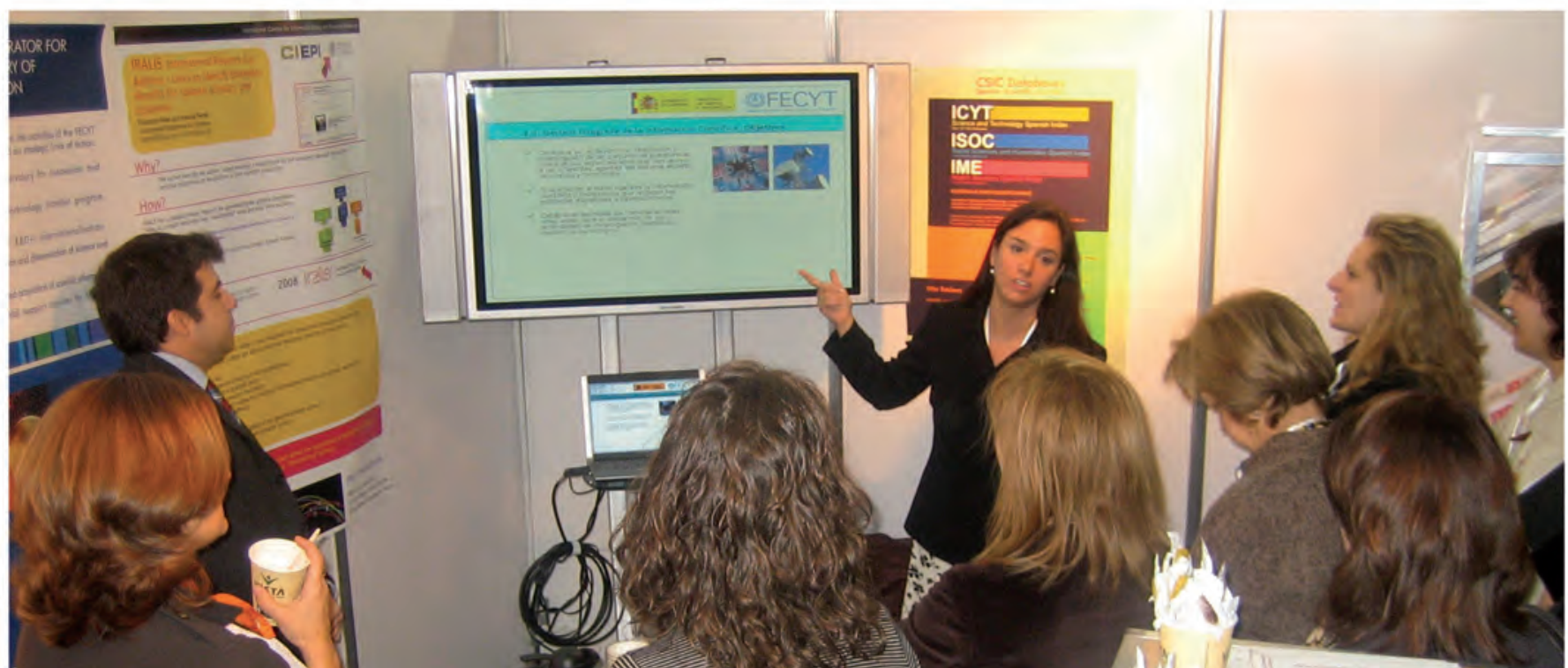




\section{Heun grupo

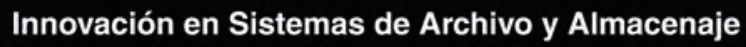

\section{Inteligencia sin relatividades}

Espacio y tiempo

son siempre variables relativas.

Salvo con la gama de soluciones de Eun, soluciones inteligentes para optimizar ambas.

Menos tiempos muertos.

Menos espacios desaprovechados.
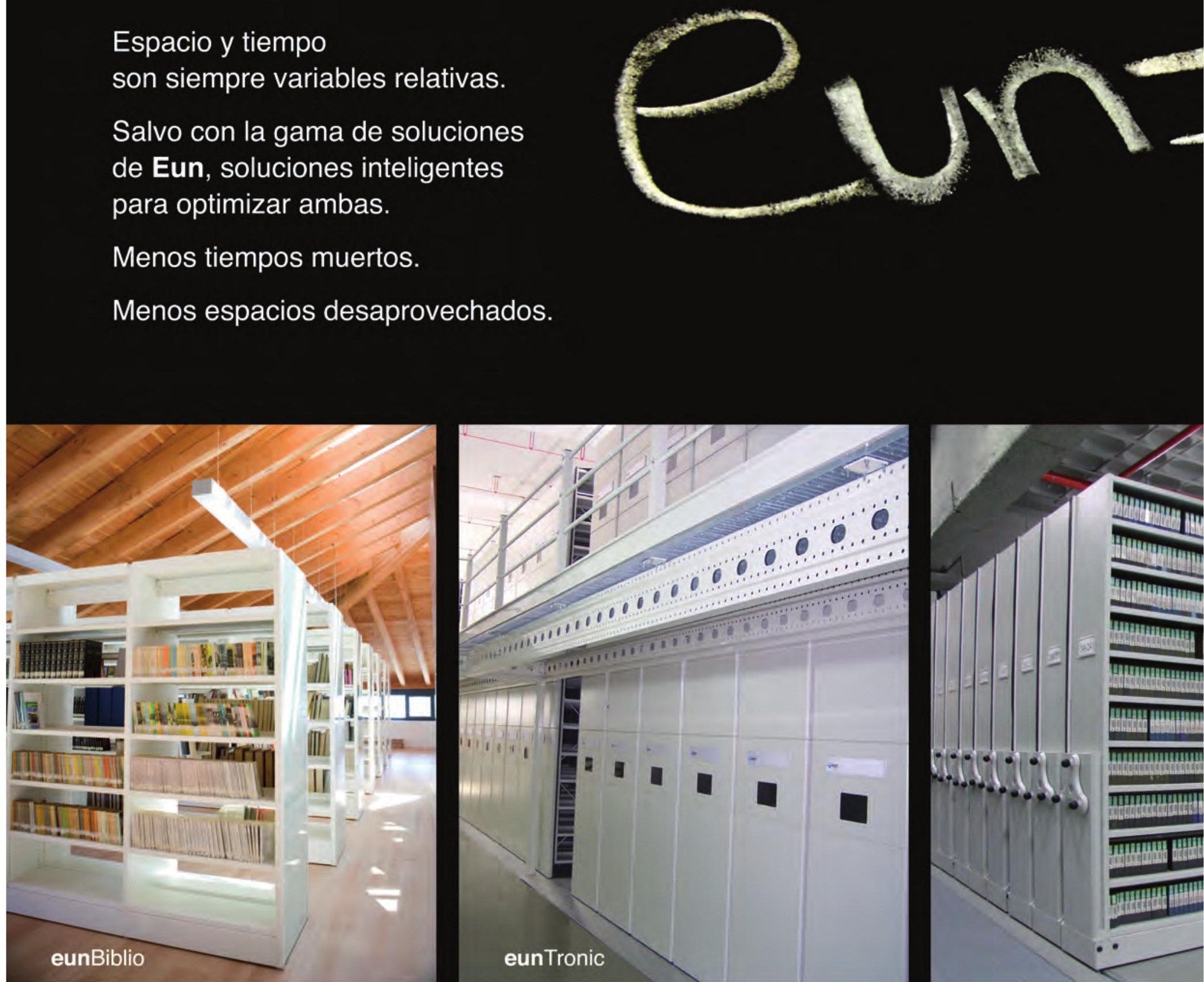

estanterías eun s.a.

$\mathrm{B}^{\circ}$ Salbatore, 17 - Apdo. 82

20200 Beasain (Gipuzkoa) • Spain

T.: +34 902114907

F.: +34902114908

E.: comercial@eun.es eun madrid s.a.

C/ Del Yunque, 27

Pol. Ind. Santa Ana

28522 Rivas Vaciamadrid (Madrid) • Spain

T.: +34902 170599

F.: +34913011307

E.: eunmadrid@eun.es eun méxico s.a. de c.v.

Paseo de la reforma, $n^{\circ} 107$ piso 6

Col. Tabacalera, c.p. 06030

México, D.F.

T. +525552088896

F.: +5255 55142547

E.: comercial@eun.com.mx 


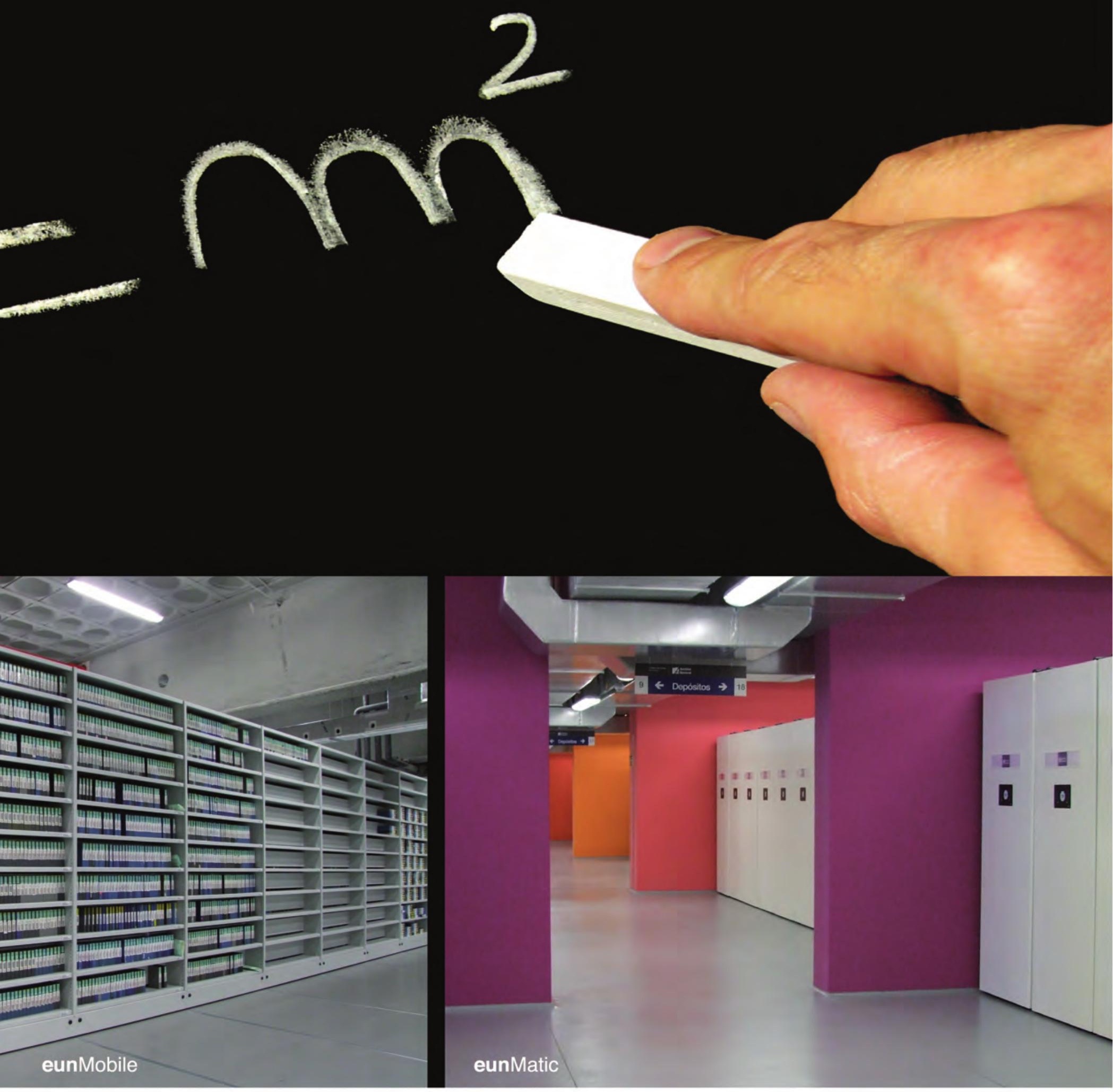

Eeun grupo

visita nuestras soluciones en:

w w w e u n e s 